\title{
Effect of low-dose human atrial natriuretic peptide on postoperative atrial fibrillation in patients undergoing pulmonary resection for lung cancer: A double-blind, placebo-controlled study
}

\author{
Takashi Nojiri, MD, ${ }^{\text {a,b }}$ Kazuhiro Yamamoto, MD, FACC, ${ }^{\mathrm{c}}$ Hajime Maeda, MD, ${ }^{\mathrm{a}}$ Yukiyasu Takeuchi, MD, ${ }^{\mathrm{a}}$ \\ Yasunobu Funakoshi, MD, ${ }^{\mathrm{a}}$ Masayoshi Inoue, $\mathrm{MD},{ }^{\mathrm{b}}$ and Meinoshin Okumura, $\mathrm{MD}^{\mathrm{b}}$
}

\begin{abstract}
Objectives: We previously reported that patients with preoperative B-type natriuretic peptide levels of $30 \mathrm{pg} / \mathrm{mL}$ or more have increased risk of postoperative atrial fibrillation after pulmonary resection. This study evaluated the effects of human atrial natriuretic peptide on postoperative atrial fibrillation in patients undergoing pulmonary resection for lung cancer.
\end{abstract}

\begin{abstract}
Methods: A prospective, randomized study was conducted with 40 patients who had preoperative elevated B-type natriuretic peptide $(\geq 30 \mathrm{pg} / \mathrm{mL})$ and underwent a scheduled pulmonary resection for lung cancer. Results were compared between patients who received low-dose human atrial natriuretic peptide and those who received a placebo. The primary end point was the incidence of postoperative atrial fibrillation during the first 4 days after surgery.
\end{abstract}

\begin{abstract}
Results: The incidence of postoperative atrial fibrillation was significantly lower in the human atrial natriuretic peptide group than in the placebo group $(10 \%$ vs $60 \% ; P<.001)$. Patients in the human atrial natriuretic peptide group also showed significantly lower white blood cell counts and C-reactive protein levels after surgery.

Conclusions: Continuous infusion of low-dose human atrial natriuretic peptide during lung cancer surgery had a prophylactic effect against postoperative atrial fibrillation after pulmonary resection in patients with preoperative elevation of B-type natriuretic peptide levels. A larger sample size is needed to establish the safety and efficacy of this intervention. (J Thorac Cardiovasc Surg 2012;143:488-94)
\end{abstract}

Atrial fibrillation (AF) is the most common type of cardiac arrhythmia encountered during the early postoperative period after a pulmonary resection procedure. ${ }^{1,2}$ Although transient in most cases, AF sometimes results in a serious outcome, including thromboembolic events and hemodynamic deterioration, which finally leads to increased mortality. ${ }^{3,4}$

Human atrial natriuretic peptide (hANP) consists of 28 amino acids and has shown a variety of biologic effects when used as treatment for heart failure in Japan. It is now known that hANP exhibits a wide range of cardioprotective effects, including antifibrosis, antihypertrophy, antiinflammation, and inhibition of sympathetic nerve activity, the renin-angiotensin-aldosterone system, and endothelin synthesis. ${ }^{5,6}$ Beneficial effects of hANP on postoperative left ventricular remodeling have been reported in patients undergoing cardiac surgery. ${ }^{7,8} \mathrm{AF}$ is often caused by

From the Department of General Thoracic Surgery, ${ }^{a}$ National Hospital Organization Toneyama Hospital, Toyonaka-City, Japan; and the Departments of General Thoracic Surgery ${ }^{\mathrm{b}}$ and Cardiology, ${ }^{\mathrm{c}}$ Osaka University Graduate School of Medicine, Suita-City, Japan.

Disclosures: Authors have nothing to disclose with regard to commercial support.

Trial registration number JPRN-UMIN 000001524.

Received for publication July 29, 2010; revisions received April 26, 2011; accepted for publication Sept 14, 2011; available ahead of print Oct 12, 2011.

Address for reprints: Takashi Nojiri, MD, Department of General Thoracic Surgery,

Toneyama National Hospital, Toneyama 5-1-1, Toyonaka City 560-8552, Osaka,

Japan (E-mail: nojirit@thoracic.med.osaka-u.ac.jp).

$0022-5223 / \$ 36.00$

Copyright $($ C 2012 by The American Association for Thoracic Surgery doi:10.1016/j.jtcvs.2011.09.003 hemodynamic, structural, and electrophysiologic changes in the atria. ${ }^{9}$ Because hANP exerts beneficial effects on hemodynamics ${ }^{10}$ and atrial electrical remodeling, ${ }^{11}$ it is plausible to expect some protective effects of hANP against postoperative $\mathrm{AF}$, and our retrospective analysis showed that the treatment with hANP was associated with the reduction of postoperative AF (unpublished data).

We previously reported that patients with lung cancer who have a preoperative plasma B-type natriuretic peptide (BNP) level of $30 \mathrm{pg} / \mathrm{mL}$ or more have increased risk of development of postoperative AF. ${ }^{12}$ The purpose of this study was to examine prospectively the effects of hANP on postoperative AF in such high-risk patients undergoing pulmonary resection for lung cancer.

\section{MATERIALS AND METHODS Patients}

This study was conducted at National Toneyama Hospital in Japan. All patients who underwent an elective pulmonary resection procedure for non-small cell lung cancer were evaluated for potential enrollment. Inclusion criterion was a preoperative BNP level of $30 \mathrm{pg} / \mathrm{mL}$ or more. The cutoff value of BNP ( $30 \mathrm{pg} / \mathrm{mL})$ was selected on the basis of our previous results, ${ }^{12}$ which showed that this cutoff value of preoperative BNP can predict the incidence of postoperative AF with high sensitivity and specificity among patients undergoing pulmonary resection for lung cancer. Exclusion criteria for this analysis were previous AF, antiarrhythmic drug use, dysthyroidism, renal failure requiring hemodialysis, repeated pulmonary resection, benign tumor, and recent ( $<1$ month) angina pectoris or myocardial infarction. Patients were not excluded if they were taking $\beta$-blockers for reasons other than cardiac arrhythmia. 

Abbreviations and Acronyms
$\mathrm{AF}=$ atrial fibrillation
$\mathrm{BNP}=\mathrm{B}$-type natriuretic peptide
$\mathrm{CRP}=\mathrm{C}$-reactive protein
hANP $=$ human atrial natriuretic peptide
$\mathrm{WBC}=$ white blood cell

\section{Study Protocol}

This was a prospective, double-blind, randomized, placebo-controlled, parallel-groups study. A description of patients screened, consenting, randomly assigned, and enrolled in the study is shown in Figure 1. Patients were randomly allocated to receive hANP or placebo. The specific randomization sequence was computer generated. In the hANP group, the subjects received hANP $(0.025 \mu \mathrm{g} / \mathrm{kg} / \mathrm{min}$ without a bolus dose; Daiichisankyo Pharmaceutical Inc, Tokyo, Japan), whereas those in the placebo group received a 5\% glucose physiologic solution for 3 days. Each treatment was started after the pulmonary artery and vein had been divided. All patients received preoperative epidural anesthesia for pain management, which usually remained in place for 2 to 4 days or until the chest drainage tubes were removed, after which patients were switched to oral analgesia. Other postoperative management methods included early ambulation and low-flow nasal oxygen supplementation, as necessary. The study protocol was approved by the institutional review board of National Toneyama Hospital, and all patients provided written informed consent before participation (trial registration number JPRN-UMIN 000001524).

\section{Measurements}

The levels of BNP were determined before surgery. The levels of atrial natriuretic peptide and $\mathrm{C}$-reactive protein (CRP), as well as white blood cell (WBC) counts, were determined before surgery and on postsurgical days 1 ,
3 , and 7, and again 1 month after surgery. The plasma concentrations of atrial natriuretic peptide and BNP were determined with an immunoradiometric assay (Shionoria ANP; Shionogi Pharmaceutical, Osaka, Japan) and a chemiluminescence enzyme immunoassay (MI02 Shionogi BNP; Shionogi Pharmaceutical), respectively. Intravenous fluid was administered at a constant rate $(80 \mathrm{~mL} / \mathrm{h})$ through a peripheral venous catheter or a central venous catheter before oral intake was resumed. Hemodynamic parameters such as systolic blood pressure, diastolic blood pressure, heart rate, and urinary volume were recorded before surgery and for the first 4 days after surgery. Transthoracic echocardiography was performed before surgery, as previously described elsewhere. ${ }^{13}$

\section{Postoperative AF}

The primary end point of the study was the incidence of postoperative AF during the first 4 days after surgery. The peak incidence of AF has been reported to occur on the second postoperative day, with most events seen during the first 4 postoperative days. ${ }^{14}$ Any episode of AF that was registered by the continuous monitoring system within the first 4 days on a rhythm strip or the 12-lead electrocardiogram that lasted for longer than 5 minutes, with or without symptoms, was defined as postoperative $\mathrm{AF}^{14}$

\section{Adverse Events}

In this study, adverse events other than $\mathrm{AF}$ were monitored for 30 days after surgery. These were defined as death, congestive heart failure, myocardial infarction, angina pectoris, pneumonia, acute respiratory failure, pulmonary embolism, and hypotension.

\section{Sample Size}

Sample size calculations for the primary end point were conducted on the basis of a retrospective analysis of our institutional database, which revealed an incidence of postoperative $\mathrm{AF}$ of $68 \%$ among patients with a preoperative $\mathrm{BNP}$ level of $30 \mathrm{pg} / \mathrm{mL}$ or more, whereas the incidence of postoperative $\mathrm{AF}$ was only $17 \%$ among patients with a preoperative BNP level of $30 \mathrm{pg} / \mathrm{mL}$ or more who were treated with hANP. We calculated the sample size with a statistical power of $80 \%(\beta=.8)$ and a significance level of $5 \%(\alpha=.05)$,

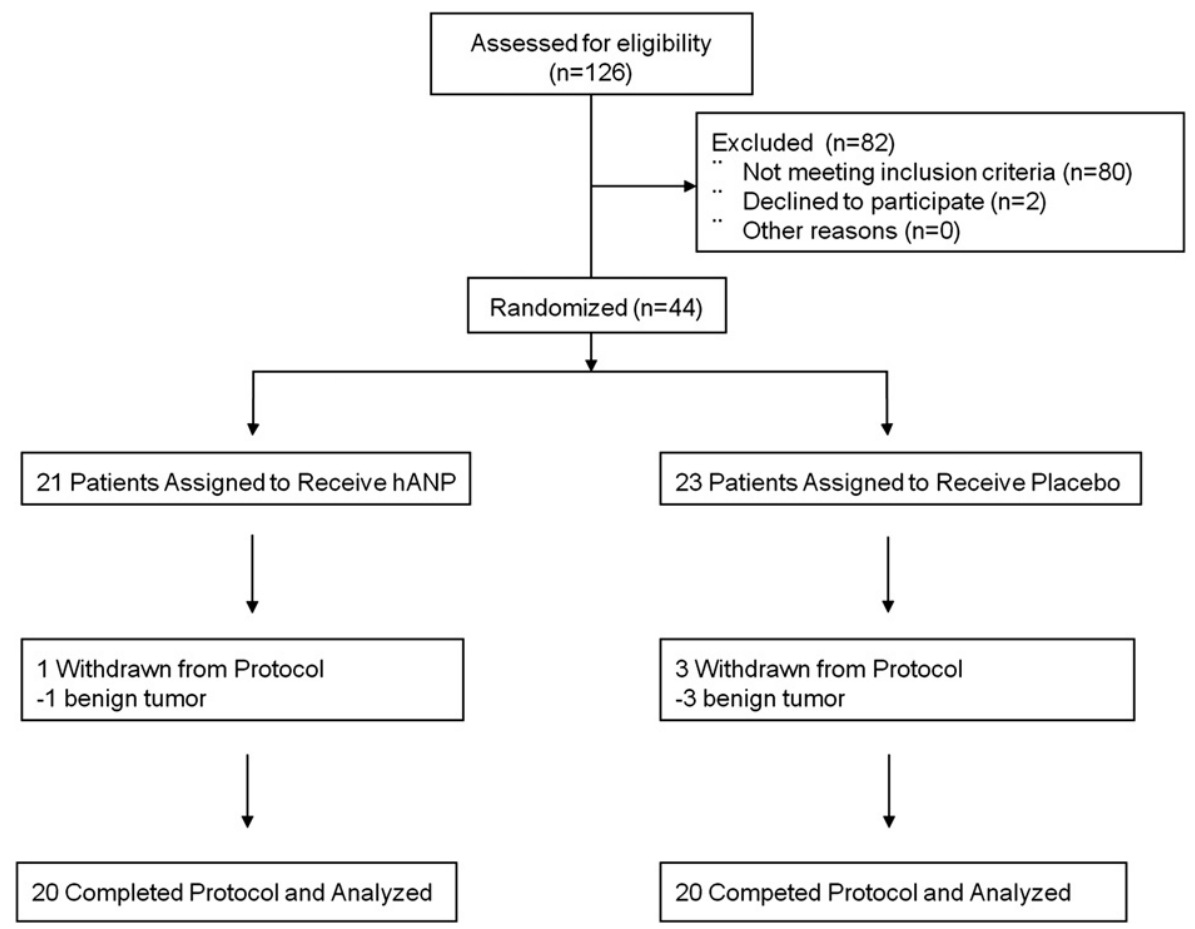

FIGURE 1. Summary of patients screened, giving consent, randomly allocated, and included in the study. hANP, Human atrial natriuretic peptide. 
which indicated that 16 patients were to be enrolled in each group. After considering a dropout rate of $20 \%$, we enrolled 20 patients for each arm.

\section{Statistical Analysis}

Data are expressed as the mean $\pm \mathrm{SD}$ or as the median with interquartile range. Comparisons among all repeated parameters were analyzed by repeated-measures analysis of variance. Comparisons between the 2 groups were assessed by Student $t$ test for normally distributed variables, by the Mann-Whitney $U$ test for nonnormally distributed variables, and by $\chi^{2}$ test for categoric variables. All data were analyzed with the SPSS statistical software package (version 11.0; IBM Corporation, Armonk, NY).

\section{RESULTS \\ Study Population}

Between April 2008 and April 2009, a total of 44 patients were enrolled in the study (Figure 1). Ultimately, 20 patients were randomly assigned to each arm and analyzed. There were no significant differences between the 2 groups with regard to baseline characteristics, surgical data, preoperative cardiopulmonary function, and serum levels of atrial natriuretic peptide and BNP (Table 1). None of the subjects

TABLE 1. Patient characteristics and preoperative cardiopulmonary function variables

\begin{tabular}{|c|c|c|c|}
\hline Variables & $\begin{array}{l}\text { hANP group } \\
(\mathbf{n}=\mathbf{2 0})\end{array}$ & $\begin{array}{l}\text { Placebo group } \\
\quad(\mathbf{n}=\mathbf{2 0})\end{array}$ & $P$ value \\
\hline Age $(y$, mean $\pm S D)$ & $73 \pm 7$ & $70 \pm 8$ & .39 \\
\hline Male (no.) & $10(50 \%)$ & $13(65 \%)$ & .17 \\
\hline Body mass index $\left(\mathrm{kg} / \mathrm{m}^{2}\right.$, mean $\left.\pm \mathrm{SD}\right)$ & $22.4 \pm 2.5$ & $22.2 \pm 3.0$ & .43 \\
\hline Hypertension (no.) & $9(45 \%)$ & $11(55 \%)$ & .54 \\
\hline Hypercholesterolemia (no.) & $8(40 \%)$ & $5(25 \%)$ & .32 \\
\hline Diabetes mellitus (no.) & $2(10 \%)$ & $2(10 \%)$ & .99 \\
\hline Ischemic heart disease (no.) & $2(10 \%)$ & $2(10 \%)$ & .99 \\
\hline \multicolumn{4}{|l|}{ Medication (no.) } \\
\hline$\beta$-Blockers & $1(5 \%)$ & $1(5 \%)$ & .99 \\
\hline Angiotensin-converting enzyme inhibitors or angiotensin receptor blockers & $2(10 \%)$ & $3(15 \%)$ & .64 \\
\hline Statins & $3(15 \%)$ & $2(10 \%)$ & .64 \\
\hline Estimated glomerular filtration rate $\left(\mathrm{mL} /\left[\mathrm{min} \cdot 1.73 \mathrm{~m}^{2}\right]\right.$, mean $\left.\pm \mathrm{SD}\right)$ & $68.2 \pm 15$ & $69.9 \pm 19$ & .78 \\
\hline \multicolumn{4}{|l|}{ Procedure (no.) } \\
\hline Wide wedge resection & $1(5 \%)$ & $2(10 \%)$ & .56 \\
\hline Segmentectomy & $1(5 \%)$ & $1(5 \%)$ & .99 \\
\hline Lobectomy & $17(85 \%)$ & $17(85 \%)$ & .99 \\
\hline Pneumonectomy & $1(5 \%)$ & $0(0 \%)$ & .32 \\
\hline Complete video-assisted thoracoscopic surgical procedure (no.) & $12(60 \%)$ & $11(55 \%)$ & .49 \\
\hline Operating time (min, mean $\pm \mathrm{SD})$ & $234 \pm 75$ & $242 \pm 80$ & .38 \\
\hline Blood loss $(\mathrm{mL}$, mean $\pm \mathrm{SD})$ & $157 \pm 58$ & $139 \pm 99$ & .41 \\
\hline Mediastinal lymph node dissection (no.) & $17(85 \%)$ & $15(75 \%)$ & .19 \\
\hline Use of catecholamines (no.) & $1(5 \%)$ & $3(15 \%)$ & .30 \\
\hline \multicolumn{4}{|l|}{ Lung cancer staging (no.) } \\
\hline IA, IB & $16(80 \%)$ & $14(70 \%)$ & .48 \\
\hline IIA, IIB & $3(15 \%)$ & $3(15 \%)$ & .99 \\
\hline IIIA, IIIB & $1(5 \%)$ & $3(15 \%)$ & .30 \\
\hline Vital capacity $(\%$ predicted, mean $\pm S D)$ & $98.0 \% \pm 21 \%$ & $103 \% \pm 19 \%$ & .28 \\
\hline $\mathrm{FEV}_{1}(\%$ predicted, mean $\pm \mathrm{SD})$ & $85.2 \% \pm 13 \%$ & $87.9 \% \pm 21 \%$ & .36 \\
\hline $\mathrm{FEV}_{1} / \mathrm{FVC}(\%$, mean $\pm \mathrm{SD})$ & $74.9 \% \pm 6.8 \%$ & $75.2 \% \pm 9.4 \%$ & .47 \\
\hline Diffusing capacity of the lung for carbon monoxide $(\%$ predicted, mean $\pm S D)$ & $94.7 \% \pm 19 \%$ & $90.6 \% \pm 22 \%$ & .28 \\
\hline $\mathrm{PaO}_{2}(\mathrm{~mm} \mathrm{Hg}$, mean $\pm \mathrm{SD})$ & $85.1 \pm 13$ & $90.4 \pm 14$ & .66 \\
\hline $\mathrm{PaCO}_{2}(\mathrm{~mm} \mathrm{Hg}$, mean $\pm \mathrm{SD})$ & $41.9 \pm 2.6$ & $39.6 \pm 3.5$ & .38 \\
\hline $\mathrm{LV}$ end-diastolic diameter $(\mathrm{mm}$, mean $\pm \mathrm{SD})$ & $41.8 \pm 3.9$ & $41.9 \pm 5.0$ & .56 \\
\hline $\mathrm{LV}$ end-systolic diameter $(\mathrm{mm}$, mean $\pm \mathrm{SD})$ & $26.8 \pm 2.4$ & $27.1 \pm 3.9$ & .21 \\
\hline LV ejection fraction $(\%)$ & $66.3 \pm 3.8$ & $65.5 \pm 4.3$ & .24 \\
\hline $\mathrm{LV}$ mass index $\left(\mathrm{g} / \mathrm{m}^{2}\right.$, mean $\left.\pm \mathrm{SD}\right)$ & $122 \pm 30$ & $107 \pm 61$ & .35 \\
\hline Left atrial diameter $(\mathrm{mm}$, mean $\pm \mathrm{SD})$ & $35.3 \pm 3.9$ & $36.1 \pm 7.4$ & .36 \\
\hline Systolic pulmonary arterial pressure $(\mathrm{mm} \mathrm{Hg}$, mean $\pm \mathrm{SD})$ & $34.4 \pm 4.8$ & $34.1 \pm 2.8$ & .87 \\
\hline $\mathrm{e}^{\prime}(\mathrm{cm} / \mathrm{s}$, mean $\pm \mathrm{SD})$ & $7.41 \pm 2.4$ & $7.28 \pm 1.1$ & .52 \\
\hline $\mathrm{E} / \mathrm{e}^{\prime}(\mathrm{mean} \pm \mathrm{SD})$ & $9.82 \pm 3.1$ & $9.50 \pm 2.5$ & .16 \\
\hline Atrial natriuretic peptide $(\mathrm{pg} / \mathrm{mL}$, mean $\pm \mathrm{SD})$ & $25.7 \pm 11$ & $28.2 \pm 18$ & .41 \\
\hline B-type natriuretic peptide $(\mathrm{pg} / \mathrm{mL}$, median and interquartile range) & $48.5(32-62)$ & $41.8(34-82)$ & .65 \\
\hline
\end{tabular}

$h A N P$, Human atrial natriuretic peptide; $F E V_{l}$, Forced expiratory ventilation in 1 second; $F V C$, forced vital capacity; $L V$, left ventricular; $e^{\prime}$, tissue Doppler mitral annular early diastolic velocity; $E / e^{\prime}$, early transmitral velocity/tissue Doppler mitral annular early diastolic velocity. 
had significant valvular disease. The mean left ventricular ejection fraction in both groups was similar and greater than $60 \%$. Both groups had relatively high preoperative BNP levels, and lobectomies were performed in most cases.

\section{Incidence of Postoperative AF}

Postoperative AF was identified in 12 subjects in the placebo group and 2 in the hANP group during the first 4 days after surgery. The incidence of postoperative AF was significantly lower in the hANP group $(10 \%$ vs $60 \% ; P<.001)$. The total group peak incidence of AF was on the first 2 postoperative days $(86 \%)$, with all events occurring on the first postoperative day in the hANP group (Figure 2). Most of the patients in whom AF developed received $\beta$-blockers or the combination of digoxin and verapamil on the onset day. All the patients with postoperative AF had restoration of sinus rhythm within 2 weeks.

\section{Adverse Events}

There were no postoperative deaths, thromboembolic events, or incidents of congestive heart failure associated with AF in either group. There were no subjects with an adverse event in the hANP group and only 1 subject with an adverse event in the placebo group. That patient had acute respiratory distress syndrome develop but recovered after a few days.

\section{Hemodynamics}

There were no statistical differences between the groups with regard to systolic blood pressure, diastolic blood pressure, heart rate, and urinary volume (Figure $3, A$ ). None of the subjects received a blood transfusion. There were also no statistical differences in the dosage of catecholamines between the groups. None of the subjects had the hANP infusion discontinued as a result of hypotension. In our analysis of urinary volume, a second peak was recognized on day 2 after surgery in the placebo group, the so-called "refilling phenomenon," whereas such a peak was not observed in the hANP group.

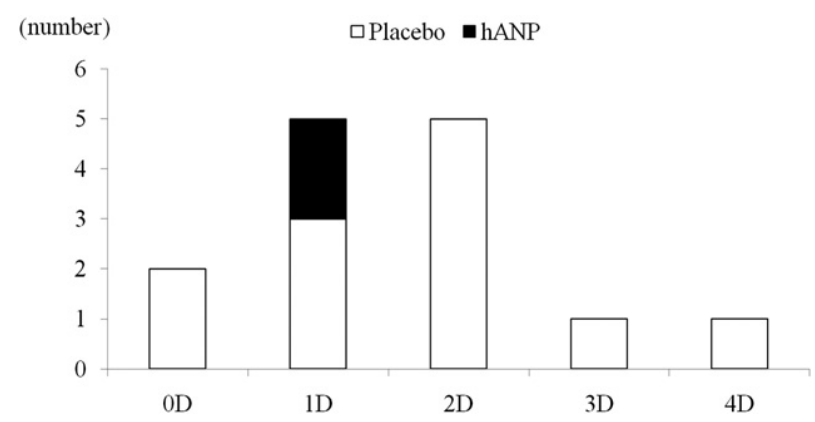

FIGURE 2. Daily distribution of postoperative atrial fibrillation in the placebo and human atrial natriuretic peptide $(h A N P)$ groups. $D$, Postoperative day.

\section{Postoperative Levels of Atrial Natriuretic Peptide}

The hANP group showed significantly higher levels of atrial natriuretic peptide than did the placebo group on days 1 and 3 after surgery. These levels decreased after the discontinuation of treatment (Figure 3,B).

\section{Postoperative WBC Counts and CRP Levels}

The hANP group showed significantly lower WBC counts and CRP levels than did the placebo group on postsurgical days 3 and 7 and 1 month after surgery (Figure 3,C).

\section{DISCUSSION}

These results are the first to show that continuous infusion of low-dose hANP has a prophylactic effect against postoperative $\mathrm{AF}$ in patients at risk for development of AF who undergo pulmonary resection for lung cancer. The infusion of low-dose hANP did not significantly change postoperative hemodynamics; however, it did decrease the postoperative WBC counts and CRP levels. These findings suggest attenuation of inflammatory changes associated with the prevention of postoperative AF. We also found that continuous infusion of low-dose hANP was well tolerated, with no clinically significant adverse effects, including hypotension, being observed. Our findings indicate that low-dose hANP is a viable treatment option to prevent postoperative $\mathrm{AF}$ in high-risk patients undergoing noncardiac thoracic surgery.

Cardinale and colleagues ${ }^{14}$ and our group ${ }^{12}$ have reported that elevated preoperative levels of $\mathrm{N}$-terminal proBNP fragment or BNP serve as remarkably accurate predictors of incidence of AF among patients undergoing noncardiac thoracic surgery. On the basis of our previous study, ${ }^{12}$ we used $30 \mathrm{pg} / \mathrm{mL}$ of plasma BNP as a cutoff value for the inclusion criteria of high-risk patients. This figure is probably justified, as indicated by the finding that the subjects in the placebo group had AF develop at a high frequency $(60 \%)$ after surgery.

Administration of hANP is considered to have various effects on postoperative $\mathrm{AF}$ in patients undergoing pulmonary resection. First, it produces vasodilatory and natriuretic effects, leading to the reduction of cardiac overload. Several studies have shown that infusion of hANP increases stroke volume index and decreases pulmonary capillary wedge pressure, while at the same time also improving hemodynamics and clinical status in patients with congestive heart failure. ${ }^{10,15}$ Sezai and coworkers, ${ }^{7}$ however, recently reported that low-dose hANP infusion $(0.02 \mu \mathrm{g} / \mathrm{kg} / \mathrm{min}) \mathrm{did}$ not significantly change hemodynamics, although it did reduce the postoperative peak level of creatine kinase isoenzyme MB and improve postoperative left ventricular function after coronary artery bypass grafting. Consistent with those results, we found no statistical differences between the hANP and placebo groups with regard to 

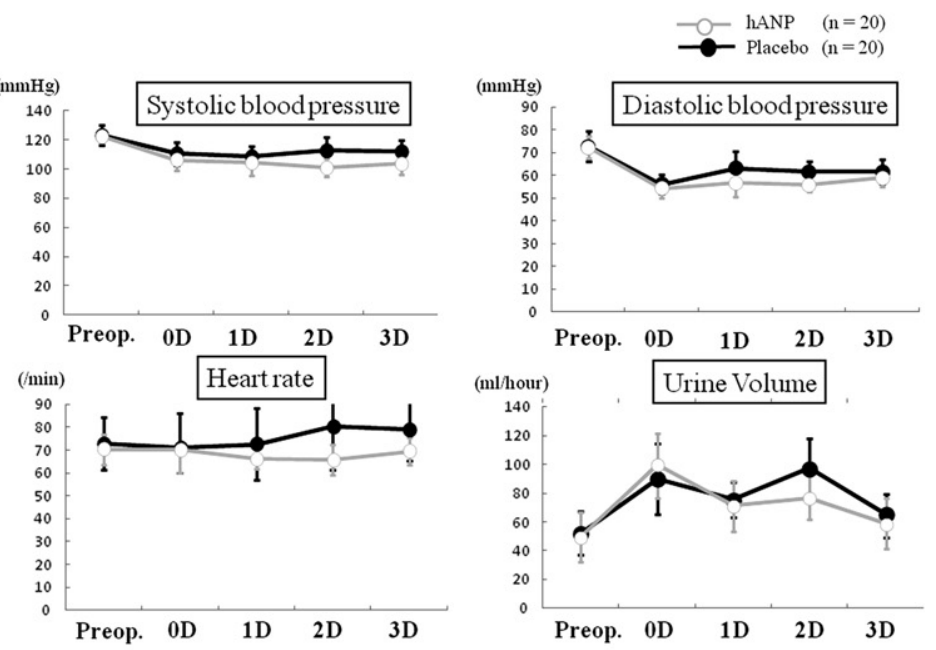

A

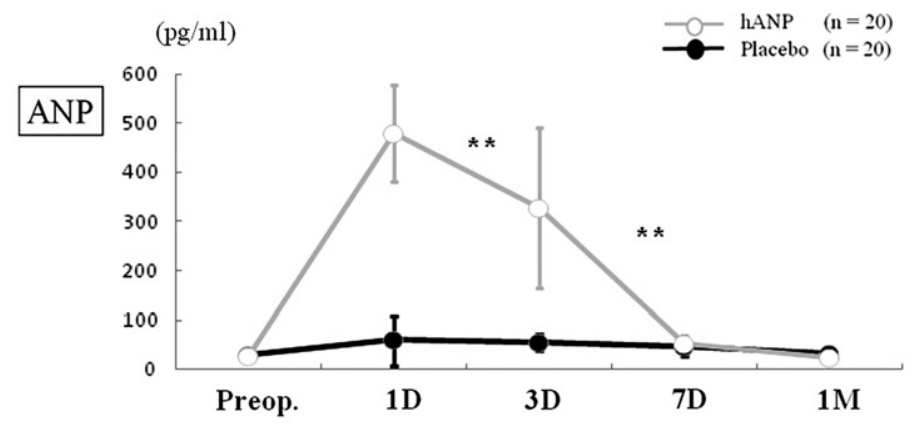

B

${ }^{*} \mathrm{p}<0.05, * * \mathrm{P}<0.001$

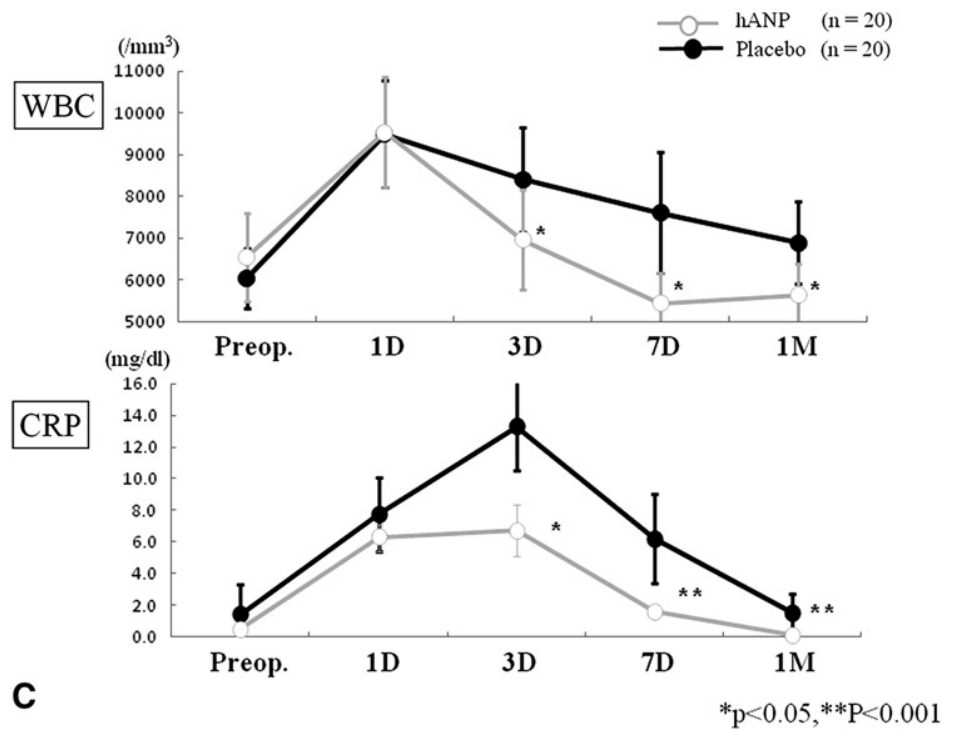

FIGURE 3. Changes from preoperative baseline (Preop.) in perioperative parameters by postoperative day $(D)$ and at 1 postoperative month $(M)$. Each point with bars shows the mean $\pm \mathrm{SD}$. A, Changes in perioperative systolic blood pressure, diastolic blood pressure, heart rate, and urinary volume. There were no statistical differences between the placebo and human atrial natriuretic peptide ( $h A N P$ ) groups. B, Changes in plasma concentrations of atrial natriuretic peptide $(A N P)$ in patients undergoing elective pulmonary resection for lung cancer who received an infusion of human atrial natriuretic peptide (hANP) or a placebo for 3 days. Double asterisk indicates $P<.001$. C, Changes in white blood cell counts (WBC) and C-reactive protein levels (CRP) in patients undergoing elective pulmonary resection for lung cancer who received an infusion of human atrial natriuretic peptide (hANP) or a placebo for 3 days. Asterisk indicates $P<.05$; double asterisk indicates $P<.001$. 
postoperative hemodynamics. In the placebo group, a second peak of urinary volume was observed on day 2 after surgery, whereas this refilling phenomenon was not observed in the hANP group. These results suggest that infusion of low-dose hANP does not significantly change hemodynamics, although it does prevent the refilling phenomenon, which could lead to a reduction in acute volume overload, resulting in prevention of postoperative AF.

Administration of hANP also inhibits inflammatory reactions. AF is often caused by structural and electrophysiologic changes in the atria that are induced by inflammation. ${ }^{16}$ Epidemiologic and clinical studies have shown an association between CRP and AF. ${ }^{17}$ Chen and colleagues ${ }^{18}$ also reported that inflammatory cell infiltration was increased in the atrial myocardium of patients with AF, whereas Ishii and associates ${ }^{19}$ found increased neutrophil cell infiltration in the atrial wall in a canine pericardiotomy and lateral right atriotomy model. In addition, the degree of atrial inflammation in the latter study was associated with proportional increases in the inhomogeneity of atrial conduction after cardiac surgery, as well as increases in the incidence and duration of AF. Moreover, antiinflammatory therapy with methylprednisolone significantly decreased the inhomogeneity of atrial conduction after the atriotomy and shortened the duration of AF. Yoshida and coworkers ${ }^{11}$ reported that exogenous atrial natriuretic peptide prevented atrial electrical remodeling in a canine rapid atrial stimulation model and speculated that this effect might have been the result of direct action on the atrial myocardium. In this study, patients in the hANP group showed significantly lower WBC counts and CRP levels after surgery than did those in the placebo group. Previous studies have also reported that hANP inhibited sympathetic nerve activity and oxidative stress. ${ }^{15}$ The administration of hANP might prevent atrial electrical remodeling through the attenuation of inflammatory changes, oxidative stress, and sympathetic nerve activation, resulting in prevention of postoperative AF.

Finally, it is important to note that the hANP group had significantly lower WBC counts and CRP levels than did the placebo group at 1 month after surgery, even though the period of hANP infusion lasted only 3 days. We believe that it is important to observe and report long-term prognoses in a larger population in future studies.

\section{Study Limitations}

This was a single-site clinical study, and thus the number and characteristics of the patients enrolled were restricted. A multicenter study with a larger sample size is necessary to validate and generalize the findings reported here and the safety of this intervention. Furthermore, echocardiographic and cardiac catheter examinations were not performed after surgery in this study, and there are no data regarding possible beneficial effects on left ventricular function or invasive hemodynamic parameters during the early period after surgery. In addition, the use of catecholamines is not common among patients undergoing pulmonary resection with preserved left ventricular function; however 3 patients in the placebo group and 1 patient in the hANP group did receive catecholamines, which may have caused the incidents of AF.

\section{CONCLUSIONS}

This study is the first to show that continuous infusion of low-dose hANP during lung cancer surgery can exert a prophylactic effect against postoperative AF after pulmonary resection without major adverse events in patients with preoperative elevation of BNP levels. Additional studies with larger sample sizes are warranted to determine whether these effects can be observed in other patients and translated into improved clinical outcomes.

We acknowledge statistical advice from Yuko Ohno, $\mathrm{PhD}$.

\section{References}

1. Cardinale D, Martinoni A, Cipolla CM, Civelli M, Lamantia G, Fiorentini C, et al. Atrial fibrillation after operation for lung cancer: clinical and prognostic significance. Ann Thorac Surg. 1999;68:1827-31.

2. Roselli EE, Murthy SC, Rice TW, Houghtaling PL, Pierce CD, Karchmer DP, et al. Atrial fibrillation complicating lung cancer resection. J Thorac Cardiovasc Surg. 2005;130:438-44.

3. Amar D, Roistacher N, Burt M, Reinsel RA, Ginsberg RJ, Wilson RS. Clinical and echocardiographic correlates of symptomatic tachydysrhythmias after noncardiac thoracic surgery. Chest. 1995;108:349-54.

4. Vaporciyan AA, Correa AM, Rice DC, Roth JA, Smythe WR, Swisher SG, et al. Risk factors associated with atrial fibrillation after noncardiac thoracic surgery: analysis of 2588 patients. J Thorac Cardiovasc Surg. 2004;127: 779-86

5. Nishikimi T, Maeda N, Matsuoka H. The role of natriuretic peptides in cardioprotection. Cardiovasc Res. 2006;69:318-28.

6. Woods RL. Cardioprotective functions of atrial natriuretic peptide and B-type natriuretic peptide: a brief review. Clin Exp Pharmacol Physiol. 2004;31: 791-4.

7. Sezai A, Hata M, Wakui S, Shiono M, Negishi N, Kasamaki Y, et al. Efficacy of low-dose continuous infusion of alpha-human atrial natriuretic peptide (hANP) during cardiac surgery: possibility of postoperative left ventricular remodeling effect. Circ J. 2006;70:1426-31.

8. Sezai A, Hata M, Niino T, Yoshitake I, Unosawa S, Wakui S, et al. Influence of continuous infusion of low-dose human atrial natriuretic peptide on renal function during cardiac surgery: a randomized controlled study. J Am Coll Cardiol. 2009;54:1058-64.

9. Nattel S, Li D, Yue L. Basic mechanisms of atrial fibrillation—very new insights into very old ideas. Annu Rev Physiol. 2000;62:51-77.

10. Saito Y, Nakao K, Nishimura K, Sugawara A, Okumura K, Obata K, et al. Clinical application of atrial natriuretic polypeptide in patients with congestive heart failure: beneficial effects on left ventricular function. Circulation. 1987;76: 115-24.

11. Yoshida T, Niwano S, Niwano H, Imaki R, Satoh D, Masaki Y, et al. Atrial natriuretic peptide (ANP) suppresses acute atrial electrical remodeling in the canine rapid atrial stimulation model. Int J Cardiol. 2008;123:147-54.

12. Nojiri T, Maeda H, Takeuchi Y, Funakoshi Y, Kimura T, Maekura R, et al. Predictive value of B-type natriuretic peptide for postoperative atrial fibrillation following pulmonary resection for lung cancer. Eur J Cardiothorac Surg. 2010;37: 787-91.

13. Nojiri T, Maeda H, Takeuchi Y, Funakoshi Y, Maekura R, Yamamoto K, et al Predictive value of preoperative tissue Doppler echocardiography for postoperative atrial fibrillation following pulmonary resection for lung cancer. $J$ Thorac Cardiovasc Surg. 2010;140:764-8. 
14. Cardinale D, Colombo A, Sandri MT, Lamantia G, Colombo N, Civelli M, et al. Increased perioperative $\mathrm{N}$-terminal pro-B-type natriuretic peptide levels predict atrial fibrillation after thoracic surgery for lung cancer. Circulation. 2007;115:1339-44.

15. Kasama S, Furuya M, Toyama T, Ichikawa S, Kurabayashi M. Effect of atrial natriuretic peptide on left ventricular remodelling in patients with acute myocardial infarction. Eur Heart J. 2008;29:1485-94.

16. Korantzopoulos P, Kolettis T, Siogas K, Goudevenos J. Atrial fibrillation and electrical remodeling: the potential role of inflammation and oxidative stress. Med Sci Monit. 2003;9:RA225-9.
17. Aviles RJ, Martin DO, Apperson-Hansen C, Houghtaling PL, Rautaharju P, Kronmal RA, et al. Inflammation as a risk factor for atrial fibrillation. Circulation. 2003;108:3006-10.

18. Chen MC, Chang JP, Liu WH, Yang CH, Chen YL, Tsai TH, et al. Increased inflammatory cell infiltration in the atrial myocardium of patients with atrial fibrillation. Am J Cardiol. 2008;102:861-5.

19. Ishii Y, Schuessler RB, Gaynor SL, Yamada K, Fu AS, Boineau JP, et al. Inflammation of atrium after cardiac surgery is associated with inhomogeneity of atrial conduction and atrial fibrillation. Circulation. 2005;111:2881-8. 